inadequacy of the idea of "dimension" as "number of parameters required". They led to a wider concept, the HausdorffBesicovitch dimension, capable of taking non-integer values. Mandelbrot coined the apt term "fractal" to denote any set whose Hausdorff-Besicovitch dimension differs from its topological dimension. He also perceived the potential applicability of fractals to the geometry of Nature. Coastlines, landscapes, the bark of trees, cell tissue, the craters on the Moon: all are arguably better modelled by a fractal than by anything smooth. Striking evidence for this view may be seen in some of the colour plates in the book - artificial craters, mountains and fjords - all utterly lifelike and convincing.

But fractal geometry runs deeper. It commonly occurs in any process having self-similarity, that is a structure (either exact or statistical) invariant under suitable scale changes. A coastline, magnified, still looks like a coastline but so do error-bursts in message transmission, energy cascades in turbulence and Brownian motion. Some techniques in physics tackle structure on many scales in a way not unsympathetic to a fractal view of the world, the renormalization group being a good example.

It is impossible to categorize this book. It is a blend of erudition (fascinating and sometimes obscure historical minutiae abound), popularization (mathematical rigour is relegated to appendices) and exposition (the reader need have little knowledge of the fields involved). Its author rightly calls it a "casebook" and a "manifesto", documenting the uses made of fractals to date and urging their

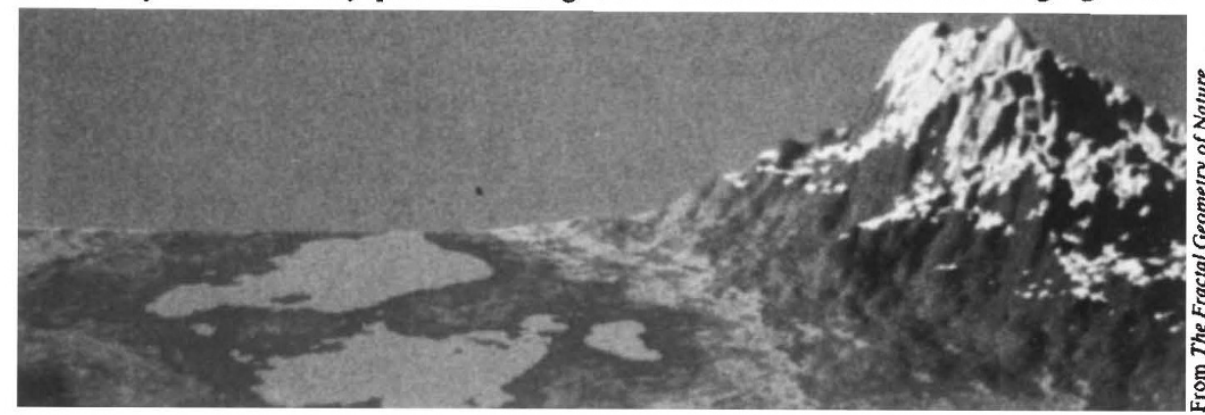

"Non-Gaussian hills that never were" - a computer generated landscape based on a version of Brownian motion related to the Gaussian distribution. The surface is a fractal of dimension greater than 2 . The zero level, chosen arbitrarily, has been interpreted as the surface of a lake. "Snow" is added to the higher elevations by a secondary colouring routine. In the original, colour illustration, the lake is blue, passing through green on the shores, shades of brown, to white on the mountain's peak. employment elsewhere. It is in addition a work of great visual beauty and the illustrations include many superb examples of computer graphics that are works of art in their own right. Mathematicians often say that mathematics is beautiful but here the beauty is evident to even the most casual reader. For this reason alone the book deserves very wide circulation indeed; but it can be recommended for another, more important, reason in that it presents a new point of view.

The theory of fractals is not yet fully mature. Many of its applications to date are purely descriptive, and some may question the relevance of fractal theory in the absence of any truly dramatic evidence of its practical importance. A notable lack is that of a theoretical underpinning, of reasons why fractals appear in certain processes, especially fluid turbulence. Possibly the theory of chaotic dynamics and strange attractors (which the author sensibly suggests be renamed fractal attractors) can be brought to bear. But none of this should detract from imaginative pioneering work. The great achievement of Mandelbrot is to have sensitized mathematicians and scientists to the fractal viewpoint, and to have pointed out the existence of a whole new and important regime for mathematical modelling.

Ian Stewart is a Lecturer in Mathematics at the Mathematics Institute, University of Warwick. He is author of Les Fractals, a cartoon book published in French by Belin.

\section{Darkness in Asia}

\section{Kenneth Mellanby}

The State of India's Environment 1982: A Citizens' Report.

By Anil Agarwal, Ravi Chopra and Kalpana Sharma.

Centre for Science and Environment/ Ravi Chopra, New Delhi: 1982. Pp.

172. Price not available.

"INDIA is rapidly becoming a vast wasteland. Indians cannot now close their eyes to the continuing degradation of their natural environment". This quotation from its summary states bluntly the conclusions of this depressing book. It is an unofficial report, sponsored by various voluntary bodies, and has been edited and largely written by three Indian authors Anil Agarwal, Ravi Chopra and Kalpana Sharma - with the help of some 30 other Indian scientists who are concerned with their country's environment.

These conclusions will make many readers despair, and adopt the views of some environmental writers of the late 1960s. Then it was suggested that India could never provide its people with decent living conditions and thus should be written off in global plans for development and recovery. While some optimism has been engendered by improvements in many Western countries, it appears that the situation in India continues to get worse.

Although some progress in science, and some industrial and agricultural im provement is reported, this is said to be at the cost of environmental damage. Thus vast amounts of soil are washed away by the monsoons, reducing agricultural potential. Water pollution gets worse -70 per cent of Indians drink filthy water and fish are poisoned while the government does little to enforce controls. Over a million hectares of forest are cut each year; planting makes up for only a fraction of this loss. Many ambitious schemes to dam rivers have had disastrous results. The air in the cities gets more polluted, levels of sulphur dioxide rising above internationally accepted standards. Disease control makes little progress - old diseases such as malaria are still rampant, new ones, including some forms of cancer, are increasing - and the death rate is no longer falling. Firewood still provides cooking energy for 90 per cent of the population but is becoming scarce. The unique wildlife is threatened.

Western readers will be surprised to find almost no comment (except for the statement that urban numbers have doubled in the last 20 years) on the subject of population. No reference is made to the efforts of India's government, not entirely unsuccessful, to reduce the rate of increase. The chapter on "People" where such information might be expected deals with the plight of fisherfolk and nomadic tribes. The authors apparently do not agree that most of the damage to the environment is connected with the vast increase in the number of Indians.

The solution proposed by Agarwal, Chopra and Sharma is to build up selfreliance at the community level, and to develop a civilization following the ascetic ideals of Mahatma Gandhi. Whether this is practicable, and whether the citizens of the world's second largest nation can be persuaded to eschew the ideals of the consumer society remains to be seen. Nonetheless the fact that these Indian writers can make this proposal is important - it would not have been acceptable from expatriate "experts". At the same time there is a risk that some of these idealistic proposals will encourage old customs and an even higher birth rate. This could, in my opinion, have ramifications which would make the environmental degradation here reported look almost insignificant.

Kenneth Mellanby is an Honorary Professoria Fellow at University College, Cardiff, and editor of the journal Environmental Pollution. 